http://dx.doi.org/10.32929/2446-8355.2020v29n2p183-203

\title{
NOVOS AGRICULTORES FAMILIARES DA MICRORREGIÃO GEOGRÁFICA DE JALES-SP: FORMAS DE ACESSO À TERRA E MUDANÇAS NAS CONDIÇÕES DE VIDA
}

\author{
Antonio Lázaro Sant ${ }^{\prime} A n a^{1 *}$, Divanir Zaffani Sant ${ }^{\prime}$ Ana $^{2}$
}

\begin{abstract}
${ }^{1}$ Professor Livre-docente em Sociologia, do Departamento de Fitotecnia, Tecnologia de Alimentos e Sócio Economia da Universidade Estadual Paulista (UNESP), Faculdade de Engenharia, Ilha Solteira, SP. *E-mail do autor correspondente: lazaro.sant@unesp.br

${ }^{2}$ Mestre em Geografia na Universidade Estadual Paulista (UNESP), Faculdade de Ciências e Tecnologia, Presidente Prudente, SP.
\end{abstract}

Recebido: 14/12/2018; Aceito: 07/05/2020

RESUMO: As perspectivas da agricultura familiar motivam preocupações, devido à escassez de filhos dispostos a assumir a propriedade e ao fato de a sucessão acontecer cada vez mais tarde; mas não há pesquisas sobre como efetivamente tem ocorrido o acesso à terra e a formação de novas unidades familiares. Este trabalho adotou uma perspectiva inovadora ao investigar as características destes novos agricultores familiares, as formas de obtenção da propriedade e as possíveis mudanças ocorridas em suas vidas, na Microrregião Geográfica (MRG) de Jales-SP. O questionário foi aplicado a 65 agricultores familiares dessa Microrregião, que possuíam até 13 anos de gestão autônoma da propriedade. Para a definição da amostra da pesquisa utilizou-se dados do Censo Agropecuário do IBGE de 2006, de informantes chaves e da própria indicação dos agricultores (método bola de neve). A análise dos resultados baseou-se na estatística descritiva. Constatou-se que mais de $70 \%$ desses novos agricultores familiares da MRG de Jales, já trabalhavam na agropecuária, mas obtiveram a propriedade por meio de compra, utilizando recursos provenientes tanto de trabalho agrícola, como não-agrícola, o que são evidências do grande esforço de parceiros, trabalhadores rurais e também filhos de agricultores familiares para concretizar o sonho de ter seu pedaço de terra e dessa forma conquistar certa autonomia técnico-produtiva e de gestão da propriedade. A avaliação desses agricultores em relação às mudanças ocorridas em suas vidas e/ou em suas rendas, depois da aquisição ou ter assumido a propriedade de forma autônoma, foi variável, mas predominantemente positiva.

Palavras-chave: Aquisição de terra. Sucessão hereditária. Estratégias de reprodução social. Agricultura familiar.

\section{NEW FAMILY FARMERS OF THE GEOGRAPHICAL MICROREGION OF JALES- SP: FORMS OF ACCESS TO THE LAND AND CHANGES IN LIVING CONDITIONS}

\begin{abstract}
The perspectives for family farming raise concerns, due to the shortage of children willing to take over the family property and the fact that succession happens later and later; but there is no research on how access to land and the formation of new family units has
\end{abstract}


effectively occurred. This paper took an innovative perspective by investigating the characteristics of these new family farmers, the ways they got the property and the possible changes that occurred in their lives, in the Microrregião Geográfica (MRG) of Jales-SP. The questionnaire was applied to 65 family farmers in this MRG, who had up to 13 years of autonomous property management. To define the research sample, were used data from the 2006 IBGE Agricultural Census, key informants and the farmers' indication (snowball method). The analysis of the results was based on descriptive statistics. It was found that more than $70 \%$ of these new family farmers from MRG of Jales, were already working in agriculture, but obtained the property through purchase, using financial resources from both agricultural and non-agricultural labor, which are evidence of the great effort of partners, rural workers and also children of family farmers to realize the dream of having their own plot of land and thus gaining some technical-productive and property management autonomy. The assessment of these farmers in relation changes in their lives and/or incomes after the acquisition or ownership of the property was variable but predominantly positive.

Key words: Land acquisition. Succession by inheritance. Social reproduction strategies. Family farming.

\section{INTRODUÇÃO}

A questão da reprodução social dos agricultores familiares tem sido um tema controverso, sendo frequente as análises que consideram como inevitável o desaparecimento da maioria dos estabelecimentos familiares, especialmente aqueles que não conseguirem atingir determinados níveis de produção e produtividade ou então inserir-se em nichos específicos de mercado.

Mendras (1978), na década 1970, na França, decretou o fim dos camponeses, enquanto outros estudiosos (MÜLLER, 1994) fizeram a mesma previsão em relação aos chamados, na época, pequenos produtores no Brasil, caso não adotassem o padrão moderno de produção agropecuária. Mas, algumas décadas depois, uma categoria social que veio encampar em uma só noção essas diversas classificações mais ou menos densas - a agricultura familiar continua presente e gerando polêmicas quando busca-se analisar o seu papel e o possível destino (BUIANAIN et al., 2014; MATTEI, 2014; HELFAND; PEREIRA; SOARES, 2014).

No Brasil a Lei 11.326 (BRASIL, 2006), estabelece os critérios quantitativos estritos para o enquadramento dos agricultores familiares, o que pode ser necessário para acesso às políticas públicas, mas nesse texto a agricultura familiar é entendida a partir de uma perspectiva que não se resume a uma forma particular de produção, mas abrange modos de vida em que a gestão do estabelecimento e o trabalho (de forma predominante) são executados pelos membros da família, a partir de distintas lógicas produtivas e de reprodução social, incluindo agricultores com diferentes trajetórias tecnológicas, de inserção ao mercado e de geração de renda (LAMARCHE, 1993; WANDERLEY, 1999). Portanto, a condição essencial para ser considerada uma unidade familiar é que o produtor e ao menos parte da família trabalhe diretamente na produção, ao mesmo tempo em que exerce a administração do estabelecimento. Pode incluir também pessoas que se aposentaram, compraram propriedade e, 
ao trabalhar e viver cotidianamente na área, se tornaram agricultores familiares, embora possam ter uma capacidade de investimento diferenciada em relação aos demais, devido ao fato de contarem com rendas não agrícolas (aposentadoria ou outra renda).

Mudanças no padrão competitividade no capitalismo moderno resultaram em avanços tecnológicos visando ganhos de escala, redução de gastos com mão-de-obra e na expulsão do campo de milhões de agricultores familiares durante a modernização conservadora da agricultura brasileira (MARTINE, 1991). O trabalho desgastante e pesado, o baixo retorno econômico das atividades agrícolas, os escassos espaços de lazer no meio rural e a falta de controle dos pais sobre os filhos, também têm provocado uma crise de sucessão na agricultura familiar no Brasil (CAMARANO; ABRAMOVAY, 1999; SILVESTRO et al., 2001; SPANEVELLO et al., 2010; SPANEVELLO et al., 2011; MATTE et al., 2015). Para buscar entender as dificuldades de sucessão, as pesquisas citadas e outras (MENDONÇA et al., 2008; BATTESTIN, 2009) analisam os contextos que contribuem para a saída dos jovens e/ou para o desinteresse de assumirem a gestão das unidades familiares, como entraves à diversificação das atividades e da renda, o trabalho penoso da agricultura e sua desvalorização social, a não conciliação entre o trabalho não-agrícola e o modo de vida rural, a precária infraestrutura geral presente no campo em várias regiões do país (educação, comunicação e especialmente lazer) e o caráter patriarcal das relações sociais no campo e na agricultura familiar em particular.

A pesquisa que originou este trabalho objetivou realizar uma análise a partir de um enfoque diferenciado, pois investigou não as perspectivas de sucessão ou de formação de novas unidades familiares, mas quem são os novos $^{1}$ agricultores familiares que, na Microrregião Geográfica (MRG) de Jales (SP), haviam efetivamente assumido, de forma autônoma, a gestão das unidades familiares a partir da década de 2000, discutindo as características das famílias, da produção e do processo obtenção da terra. Avaliou-se que essa perspectiva permite uma visão mais objetiva dos mecanismos de sucessão e de outras dinâmicas ligadas à reprodução da agricultura familiar; pois trabalha com sucessores efetivos e não potenciais, como ocorre quando se pesquisam jovens rurais e/ou a projeção realizada pelos seus pais, e inclui outros processos de obtenção da terra como a aquisição via mercado e a conquista por meio de políticas públicas (especialmente o Programa Nacional de Crédito Fundiário-PNCF, pois até à época da pesquisa não havia assentamento de reforma agrária na referida Microrregião). Neste artigo, especificamente, apresenta-se as principais características dos agricultores e dos estabelecimentos, e discute-se as diferentes formas de acesso à terra dos novos agricultores familiares pesquisados da MRG de Jales.

\section{MATERIAL E MÉTODOS}

A pesquisa foi realizada na Microrregião Geográfica de Jales, estado de São Paulo (Figura 1), a qual apresenta estrutura fundiária marcada pela forte presença de pequenos estabelecimentos familiares originários do processo de colonização da região. $\mathrm{Na}$ maioria das

\footnotetext{
${ }^{1} \mathrm{O}$ sentido de novos é de que estão, relativamente, há pouco tempo à frente da gestão da propriedade, embora a vinculação de trabalho na atividade agrícola possa ser de longa data, como o caso dos filhos de agricultores familiares que assumem tardiamente o comando da unidade familiar.
} 
propriedades a principal atividade desenvolvida é a pecuária leiteira, mas uma parcela significativa dos agricultores familiares cultiva frutas, com destaque para as uvas finas (Itália, Rubi, Benitaka, Red globe, etc.), a uva rústica (niagara rosada), os citros (laranja e limão-taiti) e a banana. Na década de 2000 aumentaram as áreas de cultivo da cana de açúcar, com a implantação de uma agroindústria em Santa Albertina e outras nas imediações da Microrregião, com impactos negativos para a agricultura familiar (SANT'ANA, 2011).

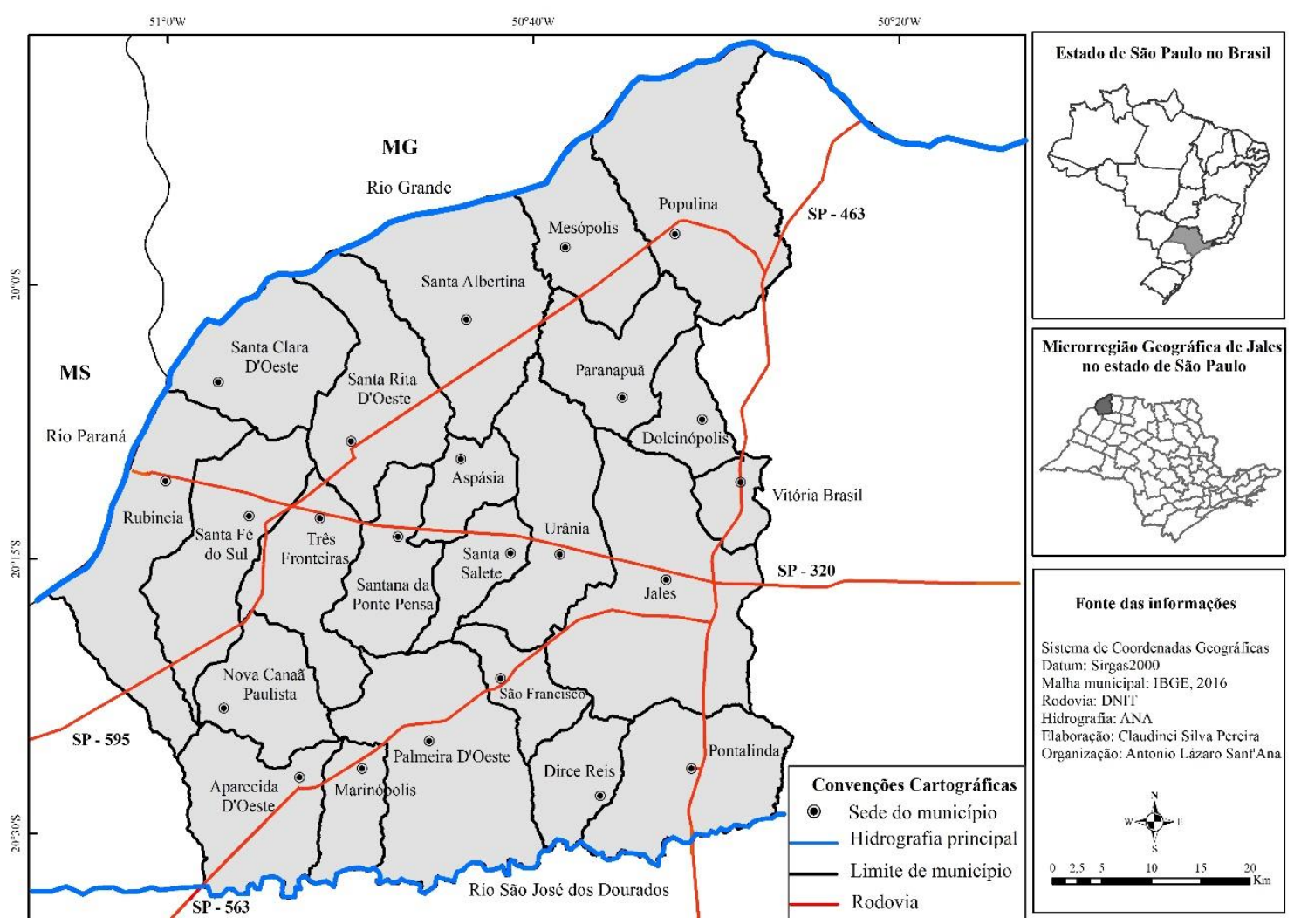

Figura 1. Mapa da Microrregião Geográfica de Jales, estado de São Paulo, com divisão dos limites territoriais dos municípios. Map of the Geographic Region of Jales, state of São Paulo, with division of the territorial limits of the county.

Fonte: IBGE (2016). IBGE (2016).

No total foram pesquisados 65 agricultores familiares com um tempo de um a treze anos de efetiva gestão (plena autonomia) do estabelecimento e que contemplavam os principais sistemas de produção da referida Microrregião, de acordo com uma tipificação preliminar feita a partir dos dados do Censo Agropecuário de 2006 e de informações obtidas junto aos técnicos que trabalhavam com extensão rural. Os principais sistemas de produção identificados foram a combinação das culturas da uva e/ou laranja com a pecuária de corte/recria; da pecuária de mista com a laranja ou outra fruta; e das olerícolas com a laranja e/ou pecuária de corte/recria; além de sistemas diversificados. O tempo limite de gestão não foi estabelecido de maneira rígida para considerá-los como novos agricultores, mas a ideia é que deveria ser um tempo menor do que aquele necessário para constituir uma nova geração de agricultores, supondo uma família em formação ${ }^{2}$.

\footnotetext{
${ }^{2}$ Geração é um conceito complexo e sujeito a várias interpretações, envolvendo aspectos sociais e culturais (FEIXA; LECCARDI, 2010), mas aqui é abordado apenas na sua dimensão biológica: uma família em formação
} 
A identificação dos agricultores que se atendiam às exigências da pesquisa foi realizada a partir de visita aos órgãos de assistência técnica e extensão rural da referida Microrregião, como o Escritório de Desenvolvimento Rural de Jales da Coordenadoria de Desenvolvimento Rural Sustentável (Ex-Coordenadoria de Assistência Técnica Integral - CATI) e às prefeituras dos demais municípios. De forma complementar também foram consultados dois alunos que cursavam pós-graduação em Agronomia da Unesp, Câmpus Ilha Solteira, e que trabalham e moram em municípios daquela Microrregião. Durante o trabalho de campo recorreu-se ainda aos próprios pesquisados que indicavam outros agricultores que julgavam se enquadrar no perfil da pesquisa - método "bola de neve" (VINUTO, 2014). A utilização de vários métodos para identificação dos agricultores respondeu ao objetivo de abranger o máximo de diversidade do público a ser pesquisado e à dificuldade um só tipo informante atender a essa abrangência.

Em função das indicações, mas sem prejuízo de buscar abranger os principais sistemas de produção, foram pesquisados agricultores em $45 \%$ dos municípios da referida Microrregião: Marinópolis, Santa Albertina, Palmeira d'Oeste, São Francisco, Urânia, Santa Fé do Sul, Rubinéia, Aspásia, Jales e Santa Salete.

Embora tenha-se buscado pesquisar todos os agricultores indicados e que realmente se enquadravam no perfil desejado na pesquisa (várias indicações mostraram-se inadequadas, especialmente em relação à autonomia efetiva do produtor), o número de pesquisados não pode definido por critério estatístico (devido à complexidade do perfil buscado na pesquisa). Portanto o universo pesquisado não representa, necessariamente, o conjunto de agricultores familiares que assumiu uma propriedade, de forma autônoma, nos treze anos anteriores à pesquisa na Microrregião, mas buscou apreender qualitativamente as características do processo, visando entender como está ocorrendo a constituição de novas unidades familiares.

O questionário, aplicado diretamente nas propriedades rurais entre os anos de 2012 e 2013, foi respondido por um dos responsáveis pelo estabelecimento (homem ou mulher), por ambos ou, em alguns casos, teve a participação de outros membros da família. Embora tenham ocorrido mudanças significativas na conjuntura nacional e regional, após esse período, este trabalho traz um retrato da situação da época e que poderá, posteriormente, ser cotejado com os dados do Censo Agropecuário do IBGE de 2017, quando estiverem disponíveis as informações sobre a agricultura familiar.

Os questionários, com perguntas abertas e fechadas (GIL, 2008) foram estruturados com dez questões, algumas com subitens, visando permitir a caracterização dos agricultores e da unidade de produção, em termos socioeconômicos. Foram levantados dados sobre o perfil socioeconômico da família; os tipos de atividades produtivas desenvolvidas; a tecnologia e mão-de-obra empregada, as formas de financiamento e gestão das atividades, as estratégias e as formas de organização da produção e da comercialização; políticas públicas que estes agricultores têm acessado; a forma de obtenção do estabelecimento (sucessão, aquisição ou outra forma) e as perspectivas dos pesquisados. O presente artigo, embora traga alguns dados

com idade média dos filhos em torno de dez a 12 anos, terá um adulto jovem em um período de 10 a 15 anos, em princípio apto para assumir funções de gestão da unidade familiar. 
gerais da pesquisa, concentra a análise no penúltimo item, relativo às diferentes formas de acesso ao estabelecimento agropecuário.

Os resultados foram tabulados e organizados, na forma de tabelas e gráficos, e analisados por meio de estatística descritiva e, no caso das perguntas abertas, categorizados a partir de semelhança semântica (temas), que é uma técnica usada na análise de conteúdo (CÂMARA, 2013). Em seguida buscou-se compará-los com outros estudos que tratam da mesma temática.

\section{RESULTADOS E DISCUSSÃO}

\section{Algumas características dos agricultores e dos estabelecimentos rurais}

Em outras pesquisas abrangendo os agricultores familiares em geral da MRG de Jales (SANT'ANA et al., 2014) constatou-se que 65\% apresentava mais de 50 anos, enquanto a $69 \%$ dos novos agricultores pesquisados possui menos de 50 anos, embora a faixa de 41 a 50 anos seja a mais frequente ( $43 \%$ do total).

Quanto à escolaridade, embora a maioria dos pesquisados (52\%) no máximo concluiu o ensino fundamental, outros $40 \%$ possuem o Ensino Médio Completo, o que representa quase o dobro do que se obteve entre os agricultores familiares em geral dessa mesma Microrregião (SANT'ANA et al., 2014). O ensino superior estava sendo cursado ou foi completado por cinco $(8 \%)$ dos pesquisados, sendo dois na área agropecuária (medicina veterinária e Agronegócios).

A área total própria dos novos agricultores familiares apresentou o mesmo padrão da MRG de Jales, que é caracterizada por pequenas unidades de produção. O tamanho médio atingiu 11,7 hectares (ha), mas a mediana foi de apenas de 6,0 ha, sendo que cerca de $85 \%$ dos pesquisados possuíam no máximo 20ha. Na MRG de Jales $88 \%$ dos estabelecimentos tinham no máximo 20ha, em 2007/08, época em que foi realizado o Levantamento Censitário das Unidades de Produção Agropecuária (LUPA) (SÃO PAULO, 2008).

Em relação às atividades agropecuárias desenvolvidas, verificou-se que a criação animal estava presente em $89 \%$ dos estabelecimentos pesquisados, mas todos também realizavam algum tipo de produção vegetal. Embora, em alguns casos, dirigida somente para o autoconsumo, a criação de aves foi a mais frequente entre os pesquisados (74\% do total), seguida pela bovinocultura de leite $(54 \%)$ e suinocultura $(45 \%)$. A cultura da laranja estava instalada em 54\% dos estabelecimentos pesquisados, seguida pela uva (40\%) e com menor frequência outras frutas, milho, olerícolas, etc.

Com base resultados obtidos no universo pesquisado é possível afirmar a esta nova geração de agricultores familiares tem um perfil social e produtivo muito semelhante à geração que os precedeu, aspecto provavelmente explicado pela origem agrícola não só dos sucessores que receberam a propriedade (ou parte dela) na forma de herança, como entre aqueles que a adquiriram, como será visto a seguir. Esta constatação reforça a questão de que são "novos" apenas no sentido de terem assumido mais recentemente, de forma autônoma, a gestão de um estabelecimento familiar. 


\section{Caracterização das diferentes formas de obtenção da terra}

Em relação à forma de sucessão ou de acesso à terra, observa-se que, isoladamente, a compra via mercado de terras, que abrangeu $40 \%$ do total de agricultores pesquisados, e a herança que totalizou $29,2 \%$ do total, foram as principais formas de obtenção das propriedades (Figura 2). Quando se analisa todas as formas de compra parcial ou total da propriedade (que inclui aquisição via PNCF, a compra combinada com herança e um caso que parte foi cedida e outra adquirida via mercado) verifica-se que foi utlizada por $43(66,2 \%)$ das 65 famílias pesquisadas; enquanto 25 (38,5\% do total) receberam por meio de herança ao menos parte da propriedade (incluindo aqueles agricultores que associaram herança ecompra). No universo pesquisado, não foram encontrados assentados da política de reforma agrária que inclui a desapropriação do imóvel por interesse social, pois somente em 2012 é que foi criado o primeiro assentamento rural na MRG de Jales (em Pontalinda, com 47 famílias).

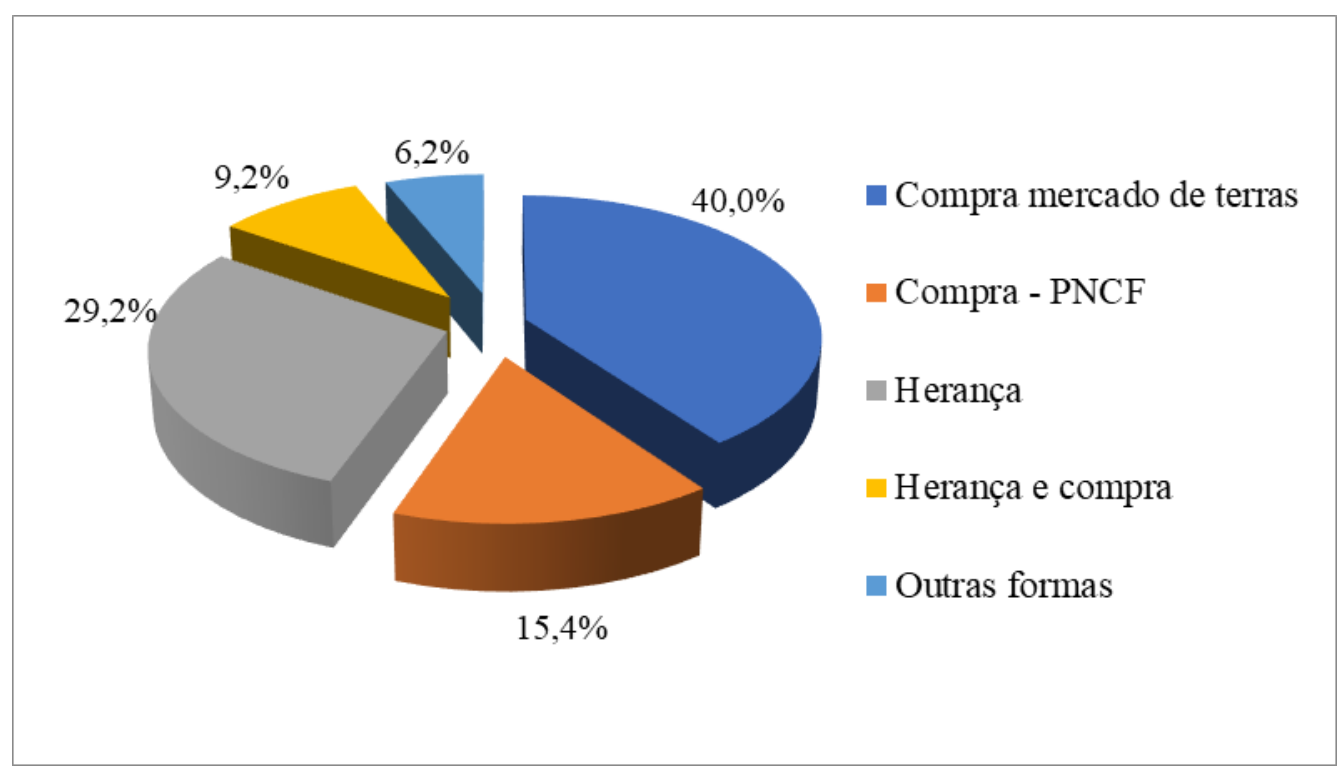

Figura 2. Distribuição (\%) de agricultores familiares pesquisados na MRG de Jales-SP, de acordo com a forma de acesso à terra. Distribution (\%) of family farmers surveyed in Region of Jales-SP according to the form of access to land.

Fonte: Autoria própria. Own authorship.

Observa-se, portanto, que a sucessão hereditária não foi a forma principal de obtenção da propriedade desses novos agricultores e sim a compra, embora $72,3 \%$ já trabalhava na agricultura. Anjos e Caldas (2009) ao estudarem a sucessão hereditária em municípios do Rio Grande do Sul, notaram que, a forma de obtenção da terra mais frequente é a herança, mas as compras de propriedade também correspondem a um percentual expressivo de $40,8 \%$ dos casos. Já Petinari, Bergamasco e Tereso (2010) notaram em seu estudo que as formas de acesso à terra, entre os agricultores familiares (em geral, não só os novos) também da MRG de Jales, variam bastante entre os municípios, pois em Marinópolis $60 \%$ das propriedades visitadas eram fruto de herança, em Santa Salete 57,1\%, porém em Santa Albertina, apenas $34,6 \%$ receberam a área por herança (a pequena amostra, por município, da presente pesquisa, não permite desagregar os dados). 
De qualquer maneira, predomina entre os agricultores pesquisados, independente da forma como tiveram acesso à unidade produtiva, já possuía experiência na atividade agrícola antes de se tornar um proprietário rural autônomo ( $74 \%$ daqueles que compraram; $88 \%$ dos herdeiros).

Em seguida discutem-se as características das duas principais formas de obtenção da propriedade: a sucessão hereditária e a compra.

\section{Obtenção da terra por meio de sucessão hereditária}

Do total de 65 famílias pesquisadas constatou-se 25 casos de herança, o que inclui tanto os 19 agricultores que somente herdaram a propriedade, como os seis produtores que herdaram uma parte da área que possuem e compraram outra parte.

Em relação a esse grupo de novos agricultores familiares, que receberam herança, verificou-se que, na maioria das propriedades visitadas, o entrevistado declarou que era comandada anteriormente pelo seu pai (56\%), aparecendo em seguida, mas com percentuais bem menores, o sogro ( $20 \%$ dos casos) e os pais (pai e mãe), citados por $12 \%$ dos pesquisados. Dois entrevistados disseram ter "herdado" das mães, mas na verdade as propriedades ainda pertencem oficialmente às mesmas, porém o usufruto é dos filhos e estes possuem plena autonomia de trabalho e investimento (Figura 3).

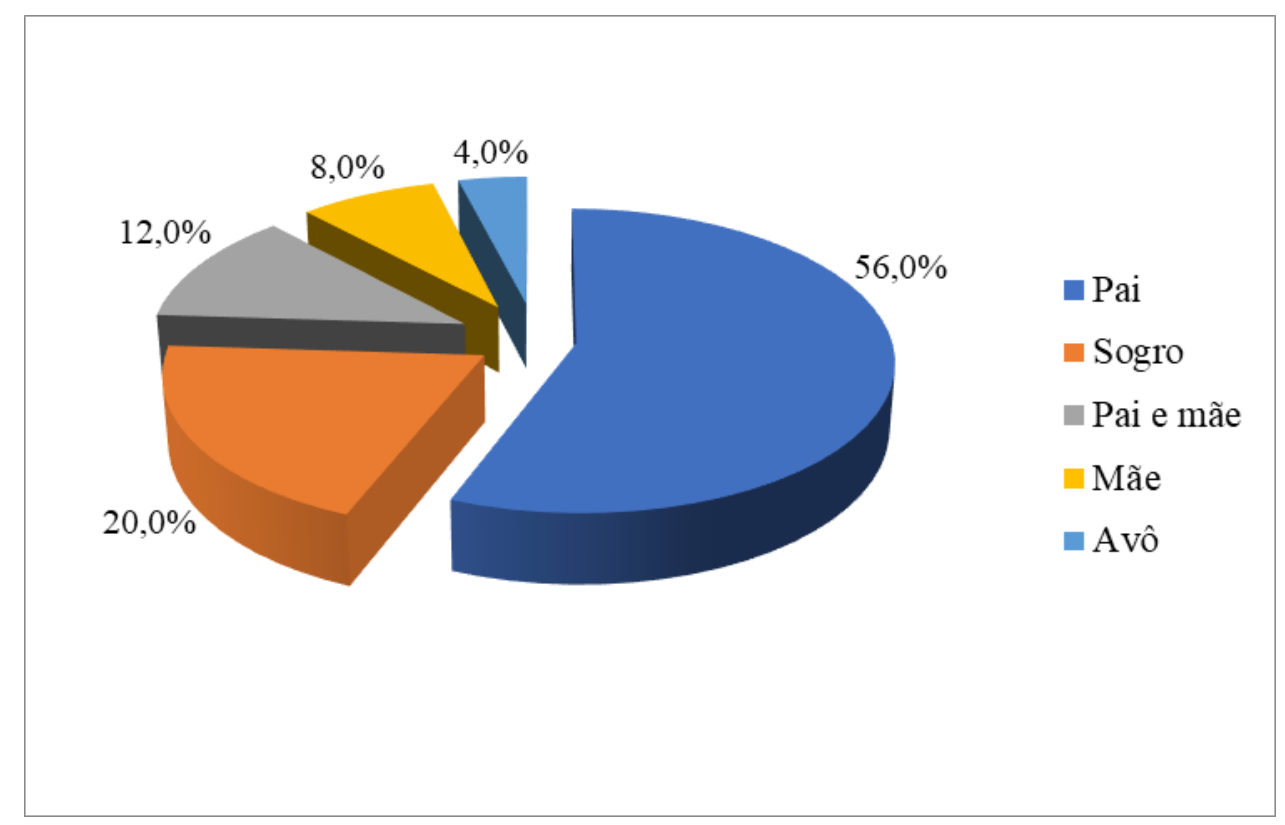

Figura 3. Distribuição (\%) de agricultores familiares pesquisados na MRG de Jales-SP que herdaram a propriedade, em função do tipo de proprietário anterior da área. Distribution (\%) of family farmers surveyed in Region of Jales-SP who inherited the property, according to the previous owner of the area.

Fonte: Autoria própria (2013). Own authorship (2013).

A declaração dos pesquisados de que herdaram do "pai" indica um viés patriarcal, pois identificam que a propriedade pertencia ao homem, quando, na verdade, trata-se um bem da família, em que a mulher também é proprietária e, na quase totalidade dos casos, construiu o patrimônio com seu trabalho no estabelecimento rural (PAULILO, 2000; FERRARI et al., 2004;.WEISHEIMER, 2009). 
Sant'Ana (2003), ao pesquisar agricultores familiares de três municípios da região noroeste do Estado de São Paulo, constatou que aproximadamente 60\%, dos chefes de famílias receberam alguma herança na forma de terra dos pais ou, em frequência bem menor, do sogro. Petinari, Bergamasco e Tereso (2010) mostraram que em Santa Albertina apenas $34,6 \%$ receberam a propriedade de herança e destes $55,5 \%$ declararam ter herdado do pai, enquanto os demais $(44,5 \%)$ citaram que a terra pertencia anteriormente ao sogro.

Entre estes 25 produtores que herdaram a propriedade, em 19 casos a divisão foi realizada de forma equivalente para todos herdeiros. Petinari, Bergamasco e Tereso (2010) obtiveram resultado semelhante, com a predominância da partição igualitária entre os filhos, mesmo quando somente uma parte desses tinha ficado e trabalhado cotidianamente na propriedade, enquanto os demais sairam e foram viver e trabalhar na cidade. Entretanto, esse tipo de divisão, em alguns casos, não foi utilizada, sendo que entre os seis entrevistados em que a propriedade não foi dividida de maneira igualitária, três agricultores não tiveram interesse em realizar a partilha, pois trabalham de maneira conjunta com os irmãos (área permaneceu indivisa); em outro caso, os irmãos não tiveram interesse na propriedade; um entrevistado (a herdeira foi a esposa) declarou que recebeu 1,2ha a menos, e por fim outro produtor disse não ter sido feita a partilha oficialmente, mas o mesmo já reliza os trabalhos de forma independente no estabelecimento.

No Brasil, apesar do Código Civil estabelecer a igualdade de condições entre todos os filhos no que se refere ao direito à herança, as regras culturais modificam a lei de acordo com os "interesses" de um ator coletivo - a família - que se impõe aos interesses individuais (CARNEIRO, 2001). Esse fator fica evidente quando tomamos por base os casos de agricultores que não pretendem realizar a divisão da propriedade, segundo as declarações de dois deles: "Não houve e nem haverá divisão, nós irmãos pretendemos trabalhar juntos. Porque se dividir irá aumentar despesas e diminuir os lucros também”" (AGRICULTOR 30, 31 ANOS, JALES); "A chácara é pequena demais e dois irmãos não trabalham ali, pois não precisam e preferiram deixar os três que trabalham" (AGRICULTOR 36, 41 ANOS, PALMEIRA D'OESTE).

Entre os seis entrevistados que dividiram a propriedade de maneira diferente, os motivos foram distintos: em um caso, composto por três irmãos, não houve a partilha pois todos os irmãos moram ainda na propriedade, e optaram por essa forma, porque já viviam ali e a casa da mãe se tornou uma área comum para todos irmãos; os outros dois casos são as falas transcritas anteriormente, que justificam a não divisão devido ao aumento das despesas e a redução de lucros; e em função do tamanho da área ser muito restrito, o que prejudicaria a produção se fosse realizada a partilha concretamente.

As práticas e falas demonstram um tipo de estratégia de trabalho muito similar ao encontrado em algumas regiões do sul do Brasil e também em Minas Gerais: a não divisão efetiva da propriedade e a permanência dos herdeiros que trabalham na mesma, constituindo ali suas famílias, reproduzindo a profissão de agricultor e mantendo o patrimônio intacto para as gerações seguintes. No Alto Jequitinhonha esse regime de terras é chamado de "terra no bolo", ou seja, são glebas familiares com formas de uso, apropriação e domínio privado e comunitário, mas indivisas no aspecto formal. Este tipo de regime, segundo Galizoni (2000), 
garante a terra em tamanho e condições ambientais mínimas necessárias à permanência das famílias. Para Almeida (1986) a dimensão corporativa da produção em família pode ser escolhida como resposta a pressões do mercado, sendo uma estratégia para se fortalecer perante problemas econômicos.

Os outros dois entrevistados que não participaram de uma divisão igualitária da propriedade, mencionaram estratégias diferentes: um entrevistado disse que sua esposa ficou com uma área bem menor, pois a parcela já possuía benfeitorias (o que pode significar certa equivalência em valor); e outro afirmou que por ele ser o mais velho e os outros irmãos já estarem empregados na cidade, estes preferiram deixá-lo na propriedade e encarregado na produção ali. Essa última estratégia de sucessão é o inverso do que ocorria até os anos 1960, segundo Anjos e Caldas (2009), justo no período que antecede o processo de modernização da agricultura e das mudanças associadas a este processo. Os autores relatam que nessa época, no Rio Grande do Sul, era o filho mais jovem de uma família que ficava com a incumbência de cuidar da propriedade e assumir também os cuidados relativos aos pais (WOORTMANN, 1995), no entanto, afirma que o herdeiro varia em função de diferentes tradições culturais conforme a região do Brasil.

Em relação aos 19 casos em que ocorreu a divisão equivalente da herança, os motivos para escolha dessa forma de partilha estão resumidos na Tabela 1.

Os motivos citados com maior frequência (26\%) foram a "vontade dos antecessores" e o "acordo entre os irmãos". O desejo dos pais ou do provedor anterior tem sido relatado também em outros trabalhos como um fator importante para a forma que assumirá a sucessão hereditária na agricultura familiar. Carneiro (2001) argumenta que o pai, responsável pela manutenção do grupo familiar, recebe nominalmente um patrimônio e o direito à propriedade que, por sua vez, não é entendido como individual; ao contrário, cabe-lhe a responsabilidade de zelar por este patrimônio coletivo, cuidando de transmiti-lo à geração subsequente. A decisão dos herdeiros ocorre geralmente no caso de espólio, mas muitas vezes também seguem recomendações que os pais fizeram antes do falecimento. Alguns agricultores justificaram esta forma de divisão por ser a "maneira mais justa e correta" (16\%) e pela "facilidade" (11\%) (Tabela 1).

Tabela 1. Motivos pelos quais a divisão ocorreu de maneira equivalente, de acordo com os agricultores pesquisados na MRG de Jales - SP que receberam herança desta maneira. Reasons why the division occurred in an equivalent manner, according to the farmers surveyed in Region of Jales - SP who received inheritance in this way.

\begin{tabular}{l|c|c}
\hline Motivos mencionados & $\mathbf{N}^{\mathbf{0}}$ de entrevistados & \% de entrevistados \\
\hline Vontade dos antecessores & 5 & 26 \\
Acordo entre irmãos & 5 & 26 \\
Maneira mais justa ou correta & 3 & 16 \\
Facilidade & 2 & 11 \\
Outras respostas & 4 & 21 \\
\hline
\end{tabular}

${ }^{1} \mathrm{O}$ cálculo da percentagem é em relação ao total de entrevistados que receberam a propriedade por meio de divisão equivalente da herança.

Fonte: Autoria própria (2013). Own authorship (2013). 
Quando questionados sobre a opinião que tinham sobre o processo de partilha ou sucessão escolhido pela família ou provedor, com exceção de um produtor que não respondeu a questão, todos os demais consideraram que a forma utilizada foi a maneira mais justa ou correta. Todavia, quando indagados de procederiam da mesma maneira com seus herdeiros, do total de 25 agricultores, 18 deles disseram que sim, reafirmando que consideravam ser uma maneira justa ou mais fácil de agir, principalmente aqueles que foram submetidos a uma partilha igualitária. Três pesquisados disseram que não procederiam da mesma maneira, mas não quanto à proporção da área e sim quanto à época da partilha, ou seja, pretendem fazer a divisão com os filhos ainda em vida. Um agricultor declarou não possuir herdeiros e outro disse que ainda não pensou no assunto, por enquanto prefere ajudar os seus descendentes de outras maneiras. Dois pesquisados não responderam. Segundo Juchem et al. (2008), a questão de sucessão familiar dentro das propriedades, normalmente, não é assunto discutido entre eles, ou seja, os pais deixam livre escolha para os filhos se querem ou não continuar trabalhando na propriedade.

Entre os seis agricultores que possuem propriedades provenientes tanto de compra como de herança, quatro deles compraram as propriedades (ou parte delas) dos irmãos e outros herdeiros que não quiseram continuar (ou iniciar) a atividade agrícola. Quando na herança são contemplados mais de um herdeiro, o que fica administrando a propriedade, com frequência, compra a parte dos demais, o que não significa, necessariamente, que o herdeiro que vendeu sua parcela deixará a agricultura, pois pode estar adquirindo outra propriedade e mantendo-se como proprietário (SCHWARTZ; SALAMONI, 2009).

Tabela 2. Motivos pelos quais os demais herdeiros, irmãos dos agricultores familiares pesquisados na MRG de Jales - SP, deixaram a propriedade. Reasons why the other heirs, brothers of the family farmers surveyed in Region of Jales - SP, left the property.

\begin{tabular}{l|c|c}
\hline $\begin{array}{l}\text { Motivos pelos quais os outros herdeiros deixaram a } \\
\text { propriedade }\end{array}$ & $\begin{array}{c}\mathbf{N}^{\mathbf{0}} \mathbf{d e} \\
\text { entrevistados }\end{array}$ & $\begin{array}{c}\text { \% de } \\
\text { entrevistados }\end{array}$ \\
\hline Trabalham/moram na área urbana & 8 & 32 \\
Dificuldade da vida no campo & 5 & 20 \\
Casamento (filhas) & 4 & 16 \\
Acharam melhor vender e pegar o dinheiro & 2 & 8 \\
Tinham outros empregos ligados à agricultura & 2 & 8 \\
Não tem experiência com trabalho no campo & 2 & 8 \\
Fizeram Curso Superior & 2 & 8 \\
Não gostam da área rural & 2 & 8 \\
Os filhos (dos herdeiros) não quiseram & 1 & 4 \\
Saiu temporariamente/pretende voltar & 1 & 4 \\
Falta de política agrícola adequada & 1 & 4 \\
Arrendaram a propriedade & 1 & 4 \\
ㅁ cálculo da percentagem é em relação ao total de entrevistados que adquiriram a propriedade por meio de \\
herança de maneira equivalente. \\
Fonte: Autoria própria (2013). Own authorship (2013).
\end{tabular}


Dentre aqueles que receberam herança revelaram que, em média, do total de herdeiros (irmãos/irmãs ou cunhados/cunhadas) $56 \%$ trabalham e/ou moram na propriedade. Os motivos pelos quais os demais herdeiros deixaram a propriedade e/ou o meio rural estão elencados na Tabela 2.

De acordo com os agricultores pesquisados o motivo principal da não permanência de parte dos herdeiros na terra é que não moravam/trabalhavam mais na propriedade e estavam adaptados à vida na área urbana (32\%); em seguida $20 \%$ dos agricultores citaram a dificuldade da vida no campo e $16 \%$ dos pesquisados o casamento. É necessário ressaltar que o casamento foi citado pelos entrevistados se referindo às herdeiras, na maioria dos casos pelo fato de suas irmãs terem casado com pessoas que não possuíam vínculo com o rural.

Para Favareto (2007) é muito comum que as filhas passem a habitar núcleos urbanos relativamente próximos, diante da falta de espaço na lógica de transmissão patrimonial no seio da família, em busca de continuar a estudar ou para trabalhar. Neste novo ambiente frequentemente elas acabam contraindo o matrimônio, em geral tendo como parceiros pessoas não mais vinculadas à atividade agrícola. Para Schwartz e Salamoni (2009) de acordo com a realidade de São Lourenço do Sul-RS, a mulher geralmente não herda terras, pois constituirá uma nova família, mesmo quando ocorre à herança, a parte das herdeiras costuma ser repassada para um dos irmãos por meio de compra (como constatou-se também na presente pesquisa). Também Paulilo (2000) explica a lógica que leva a exclusão das mulheres:

[...] for preciso excluir alguém, as mulheres são as primeiras a serem escolhidas. Elas são sempre consideradas como "filhas ou esposas de agricultor", termo que identifica tanto as que trabalham nos campos com as que não o fazem. Também quando a terra pertence à mulher por herança, é o marido considerado o responsável (PAULILO, 2000, p. 5).

Foram mencionados ainda vários outros motivos que levaram a não permanência na terra, incluindo a falta de experiência no trabalho agrícola, não gostar do meio rural, ter outras profissões (supostamente mais vantajosas), entre outras justificativas. Cabe destacar que ter ensino superior foi citado por dois entrevistados como razão para não assumir a propriedade ${ }^{3}$ (Tabela 2).

Verificou-se também que quase todos os herdeiros já moravam e trabalhavam na agricultura antes de receber a propriedade rural. Apenas três agricultores (12\% dos herdeiros pesquisados) não moravam e trabalhavam no estabelecimento familiar na época da partilha.

Entre os 22 herdeiros que já moravam ou trabalhavam na agricultura antes de herdar a propriedade, apenas quatro disseram que realizavam essa atividade em outra propriedade, em sua maioria como empregados, enquanto 18 agricultores já viviam e trabalhavam na propriedade herdada, caracterizando a sucessão típica da agricultura familiar.

A média de idade dos pesquisados é 45 anos e considerando que assumiram a propriedade numa faixa de tempo de um a treze anos, conclui-se que cerca da metade desses agricultores familiares herdou (ou comprou) a propriedade rural quando tinha mais de 40 anos

\footnotetext{
${ }^{3}$ Esta oposição entre estudo mais avançados e permanência no trabalho agrícola na propriedade já foi constatado por outros autores, como Silvestro et al. (2001) e Menezes et al. (2010).
} 
de idade. Pode-se afirmar, portanto, que é um processo que ocorre de forma relativamente tardia, pois nessa faixa etária a maioria dos indivíduos já constituiu família e possui até possíveis sucessores (filhos adultos e alguns casados) para um patrimônio que acabou de herdar.

Em relação às mudanças na vida após conseguir a autonomia na propriedade, $36 \%$ deste grupo de pesquisados disseram que após a herança aumentou sua autonomia e independência (Tabela 3): "Mudou, pois agora sei o que é meu e posso fazer o que quero, assim é melhor (antes tinha os outros irmãos)" (AGRICULTOR 4, 46 ANOS, SANTA SALETE); "Melhorou porque posso mandar e fazer o que quero, além de melhorar a situação financeira" (AGRICULTORA 06, 38 ANOS, ASPÁSIA); "Mais independência, antes dependia da decisão do pai” (AGRICULTOR 27, 46 ANOS, MARINÓPOLIS).

Tabela 3. Possíveis mudanças na vida após receber a propriedade como herança, entre os agricultores familiares pesquisados na MRG de Jales - SP. Possible changes in life after receiving the property as inheritance, among the family farmers surveyed in Region of Jales $S P$.

\begin{tabular}{l|c|c}
\hline Mudanças mencionadas & 作 & $\begin{array}{c}\text { \% de } \\
\text { entrevistados }\end{array}$ \\
\hline Maior autonomia/independência & 8 & 36 \\
Não houve mudanças & 6 & 27 \\
Melhorou financeiramente & 4 & 18 \\
Aumentou a produção & 2 & 9 \\
Aumentou o trabalho & 2 & 9 \\
Aumentou a responsabilidade & 2 & 9 \\
Não respondeu & 4 & 18 \\
\hline${ }^{1}$ O cálculo da percentagem é em relação ao total de entrevistados que adquiriram a propriedade por meio de \\
herança. \\
Fonte: Autoria própria (2013). Own authorship (2013).
\end{tabular}

Por outro lado, $27 \%$ dos agricultores declararam não ter percebido mudanças significativas em sua vida após a herança, porém pode-se notar nas declarações dos agricultores que os motivos de não ter percebido mudanças variam bastante, desde a pouca diferença das técnicas utilizadas anteriormente, até perdas na produção com problemas fitossanitários (doença) ou mesmo a pré-existência de independência quase completa (Tabela $3)$.

Com menor frequência também foram citados outros fatores favoráveis, como a melhoria econômica (18\%) e o aumento da produção (9\%); ou fatores não necessariamente favoráveis, como aumento da responsabilidade (9\%) e do trabalho (9\%) (Tabela 3). De modo predominante os agricultores pesquisados consideraram como amplamente positivas as mudanças ocorridas.

Entre os três agricultores que viviam ou trabalhavam na área urbana, observou que tinham diferentes ocupações: assistente administrativo, motorista de ônibus e médico veterinário em clínica de animais domésticos. Quanto aos motivos para terem mudado de atividade, tanto foi a busca da tranquilidade do campo, como a avaliação de que a agricultura 
é bom investimento. Em relação à satisfação relativa à mudança ocorrida, os três entrevistados tiveram respostas distintas. Um deles disse que após deixar a capital para o interior notou muitas mudanças em sua vida, principalmente melhorias no aspecto econômico. Outro disse que ainda não houve mudanças de renda, porém está muito satisfeito com a nova atividade. $\mathrm{E}$ o último afirmou não ver mudança após ter herdado a propriedade, pois já morava na área rural seis anos antes de herdá-la (total de 13 anos na agricultura).

\section{Obtenção da terra por meio de compra}

A compra de ao menos parte da propriedade envolveu 43 do total de 65 agricultores pesquisados, sendo que 36 agricultores haviam obtido a terra somente mediante à compra, enquanto seis herdaram uma parte e compraram outra parte das terras que possuem (estes mesmos agricultores também foram incluídos na análise daqueles que receberam herança, pois participaram das duas experiências) e comprou parte da terra e outra parte tinha sido cedida pelo pai (mas não constituia-se, ainda, em herança).

A forma como ocorreu a compra dessas propriedades foram agrupadas em categorias de acordo com a fonte dos recursos (Tabela 4).

Tabela 4. A forma que ocorreu a compra da propriedade pelos agricultores familiares pesquisados na MRG de Jales - SP. The form that occurred the purchase of the property by the familiar farmers surveyed in Region of Jales - SP.

\begin{tabular}{l|c|c}
\hline Forma de aquisição da propriedade & $\begin{array}{c}\mathbf{N}^{\mathbf{0}} \mathbf{d e} \\
\text { entrevistados }\end{array}$ & $\begin{array}{c}\text { \% de } \\
\text { entrevistados }^{\mathbf{1}}\end{array}$ \\
\hline Recursos de trabalho agrícola & 20 & 47 \\
(parceiro/meeiro/assalariado) & 14 & 33 \\
Recursos de rendas não agrícolas & 10 & 23 \\
Financiamento por meio do PNCF & & \\
\hline
\end{tabular}

${ }^{1} \mathrm{O}$ cálculo da percentagem é em relação ao total de entrevistados que adquiriram a propriedade (ou parte da mesma) por meio de compra. Tabela com repetição (dois agricultores usaram duas fontes diferentes).

Fonte: Autoria própria (2013). Own authorship (2013).

Nota-se que a forma mais recorrente, abrangendo $48 \%$ dos casos, envolveu a utilização de recursos advindos de trabalho agrícola, tanto como parceiro ou meeiro (propriedades de terceiros ou dos pais) ou, em alguns casos, como trabalhador assalariado. A segunda forma de aquisição, utilizada por $33 \%$ daqueles que compraram uma propriedade, teve como origem dos recursos rendas não-agrícolas, obtidas por meio do trabalho, mas também de aposentadoria. A terceira forma de aquisição, citada por $24 \%$ dos pesquisados (10 agricultores) foi a compra por meio de associações de agricultores constituídas para acessar ao financiamento do Programa Nacional de Crédito Fundiário-PNCF (Tabela 4). Os pesquisados identificam o PNCF como Banco da Terra, que era nome de Programa semelhante vigente até 2002.

Em relação ao total de agricultores que compraram a propriedade, com recursos provenientes de atividade não-agrícola, predminaram aqueles que exerciam atividades na área urbana sem nenhuma ligação com o setor agropecuário. Alguns, no entanto, tinham sua atividade principal na cidade, porém prestavam serviços em propriedades rurais, como o caso de um técnico em agropecuária e um funcionário público: "Trabalhava antes como tratorista 
na prefeitura e trabalhava na folga em outros sítios"(AGRICULTOR 45, 50 ANOS, SÃO FRANCISCO).

Constatou-se que as profissões desses quatorze entrevistados, que realizavam atividades não-agrícolas, eram bem diversas: operário ou encarregado em indústrias (4), chefe de cozinha, motorista de ônibus e outros não especificaram. Quatro agricultores conseguiram adquirir a propriedade após passarem alguns anos no exterior, exercendo atividades nãoagrícolas (três no Japão e um na Inglaterra), um número expressivo, considerando o tamanho da amostra.

Os agricultores que utilizaram recursos PNCF estão vinculados a duas associações criadas nos munícipios de Rubinéia e Santa Fé do Sul, denominadas, respectivamente, Associação de Pequenos Produtores do Alto Bacuri (Rubineia) e Associação de Pequenos Produtores de Santa Fé do Sul. Por meio desse Programa grupos de interessados (associados) podem obter financiamento público para aquisição de um imóvel rural, desde que comprovem mais de cinco anos de experiência rural nos últimos 15 anos, além de ter renda familiar anual e o patrimônio dentro dos parâmetros do Programa, que era de até $\mathrm{R} \$ 15$ mil para a renda e de até R\$ 30 mil para o patrimônio na época (2003-04) e modalidade (Consolidação da Agricultura Familiar - CAF) em que os agricultores tiveram acesso ao PNCF (GALINDO et al., 2016).

Com esta finalidade de adquirir um pedaço de terra, juntaram-se de ínicio 48 agricultores para comprar uma propriedade por meio do PNCF, porém não havia uma área grande o suficiente na região para tantos lotes, cujo proprietário estivesse disposto a vender. Decidiram então subdividir-se em 22 famílias que formaram a Associação de Pequenos Produtores de Santa Fé do Sul e os outras 26 famílias constituiram a Associação dos Pequenos Produtores do Alto Bacuri; e seguida compraram duas propriedades.

O motivo principal que levou essas pessoas a comprarem um imóvel rural, foi principalmente o sonho em ter sua própria terra ou négocio ( $25,6 \%$ dos casos), porém a vontade de parar de trabalhar como empregado apareceu também com um percentual expressivo (23,3\%) (Tabela 5). Pode-se inferir que as duas razões são complementares, pois muitas vezes esse agricultores sonha em ter sua propriedade em função de querer parar de trabalhar como empregado, seja em outra propriedade rural, seja em algum emprego urbano.

Em todos os casos de saída para o exterior o objetivo foi conseguir o recurso necessário para a compra uma propriedade rural: "Porque eu já vivia da agricultura e já era sonho, fui criado na roça e não sei fazer outra coisa" (AGRICULTOR 26, 50 ANOS, MARINÓPOLIS); "Era um sonho ter um pedacinho de terra, trabalhar no que é nosso!" (AGRICULTOR 35, 41 ANOS, PALMEIRA D'OESTE); "Sempre trabalhei na área rural, comecei como empregado do meu pai, com isso quis comprar uma para ser dono" (AGRICULTOR 47, 51 ANOS, SÃO FRANCISCO); "Porque não preciso trabalhar para os outros, me sinto melhor" (AGRICULTOR 10, 51 ANOS, URÂNIA).

O fato de gostar ou preferir o trabalho agrícola e a vida no meio rural foi citado $16,3 \%$ dos agricultores como razão que os levou a adquirir a propriedade; enquanto 11,6\% justificaram que já trabalhavam no meio rural, um motivo próximo daqueles $(9,3 \%)$ que 
alegaram que ser agricultor era sua única profissão (o que sabiam fazer). Avaliações econômicas, como o aumento da produção ou consideração de que a terra é um bom investimento foram citadas por 9,3\% e 7,0\% daqueles que adquiriram uma propriedade, respectivamente. $\mathrm{O}$ atendimento de preferências do marido ou filhos foi citado por 7,0\%, enquanto outros motivos foram lembrados com menor frequência (Tabela 5).

Tabela 5. Motivos que levaram à compra da propriedade pelos agricultores familiares pesquisados na MRG de Jales - SP. Reasons that led to the purchase of the property by the family farmers surveyed in Region of Jales - SP.

\begin{tabular}{l|c|c}
\hline Motivos que levaram a compra da propriedade & $\begin{array}{c}\mathbf{N}^{\mathbf{0}} \mathbf{d e} \\
\text { entrevistados }\end{array}$ & $\begin{array}{c}\text { \% de } \\
\text { entrevistados }\end{array}$ \\
\hline Sonho em ter seu própria(o) terra/negócio & 11 & 25,6 \\
Parar de trabalhar como empregado & 10 & 23,3 \\
Prefere/gosta do meio rural/trabalho agrícola & 7 & 16,3 \\
Já trabalhava na área rural/agrícola & 5 & 11,6 \\
Aumentar produção/área/renda & 4 & 9,3 \\
Sua única profissão é a de agricultor & 4 & 9,3 \\
Investimento & 3 & 7,0 \\
Marido/fillhos gostam do rural & 3 & 7,0 \\
Falta de emprego urbano & 2 & 4,7 \\
Tranquilidade da área rural & 2 & 4,7 \\
Outros motivos & 4 & 9,3 \\
\hline
\end{tabular}

${ }^{1} \mathrm{O}$ cálculo da porcentagem é em relação ao total de entrevistados que adquiriram a propriedade por meio de compra.

Fonte: Autoria própria (2013). Own authorship (2013).

Em relação às mudanças na vida dos entrevistados após a compra da propriedade, do total de 43 agricultores que são caracterizados por esse perfil, apenas sete $(16,3 \%)$ disseram que não notaram nenhuma mudança significativa em sua condição ou qualidade de vida depois da aquisição. A análise das mudanças, enumeradas pelos demais, indicou que 31 delas foram de caráter positivo e apenas cinco apontaram mudanças que podem ser interpretadas como negativas. As mudanças positivas mais mencionadas foram a melhoria financeira $(25,6 \%)$ e a maior liberdade e autonomia (20,9\%), seguidas de outras duas respostas interligadas a esta última questão, "a maior tranquilidade no trabalho ou vida" (16,3\%) e a condição de que "deixou de trabalhar de empregado" (14\%). Pode-se perceber que a maioria dos entrevistados possui uma visão otimista em relação à vida e ao trabalho no meio rural e que os objetivos que almejavam quando compraram (principalmente o sonho de ter sua terra e parar de trabalhar como empregado) foram, em parte, alcançados (Tabela 6).

A terra, de modo geral, para os agricultores familiares, não é apenas um espaço de produção, mas também de vida (WANDERLEY, 2009), portanto a satisfação por tê-la conquistado perpassa pelos diferentes grupos de agricultores e formas pela quais a obtiveram, seja via reforma agrária, PNCF, herança, aquisição com recursos próprios de forma individual ou coletiva (ALVES, 2006; SANT'ANA et al., 2008; MAIA et al., 2018)), assim como os fazem, muitas vezes, a rejeitar formas de arendamento que envolvam outras categorias sociais (CASTRO, 2017). 
Porém, como já citado, nem todos os agricultoreses pesquisados declararam ter tido uma melhoria em sua vida. As mudanças negativas citadas, com maior frequência, foram o aumento da carga de trabalho $(9,3 \%)$ e o aumento de despesas, com consequente diminuição de lucros (este aspecto citado por um agricultores e incluido em "outras respostas") (Tabela $6)$.

Tabela 6. Principais mudanças na vida dos agricultores familiares pesquisados na MRG de Jales - SP, após a compra da propriedade. Major changes in the lives of the family farmers surveyed in Region of Jales - SP after the purchase of the property.

\begin{tabular}{l|c|c}
\hline $\begin{array}{l}\text { Principais mudanças na vida após a compra } \\
\text { da propriedade }\end{array}$ & $\mathbf{N}^{\mathbf{0}}$ de entrevistados & $\begin{array}{c}\text { \% de } \\
\text { entrevistados }\end{array}$ \\
\hline Melhorou financeiramente & 11 & 25,6 \\
Maior autonomia/liberdade & 9 & 20,9 \\
Maior tranquilidade no trabalho ou vida & 7 & 16,3 \\
Deixou de trabalhar como empregado & 6 & 14,0 \\
Passou a trabalhar mais & 4 & 9,3 \\
Nada mudou & 7 & 18,6 \\
Financeiramente não mudou & 2 & 4,7 \\
Outras respostas & 8 & 18,6 \\
\hline
\end{tabular}

${ }^{1} \mathrm{O}$ cálculo da percentagem é em relação ao total de entrevistados que adquiriram a propriedade por meio de compra.

Fonte: Autoria própria (2013). Own authorship (2013).

O comportamento relativamente semelhante das categorias (compra e herança) pode ser explicado pelo fato de que a maioria dos novos agricultores familiares que compraram uma propriedade, já possuía contato com o meio rural por trabalharem em outras áreas como parceiros, arrendatários, meeiros e até como funcionários assalariados, (embora alguns com longo período sem contato com o campo). E no caso dos agricultores que herdaram é mais comum que tenham tido o contato com trabalho agrícola desde muito cedo, por morarem ali e as atividades já fazerem parte de seu cotidiano na propriedade dos pais. É o que constatam também, Silvestro et al. (2001), no oeste de Santa Catarina, também constataram que os filhos(as) dos agricultores familiares integravam-se precocemente aos processos trabalho, acompanhando e ajudando os pais em algumas tarefas, e quando adolescentes já dominavam não somente as técnicas de trabalho, como os aspectos relacionados à gestão do estabelecimento.

\section{CONCLUSÃO}

Os resultados da pesquisa mostraram que cerca de dois terços dos novos agricultores familiares pesquisados, na Microrregião Geográfica de Jales, tiveram acesso à propriedade por meio da compra (alguns com auxílio de recursos de herança), enquanto em menos de $40 \%$ dos casos envolveu a sucessão hereditária, embora mais de $70 \%$ já trabalhava na agricultura. Estes dados evidenciam que alguns parceiros e até trabalhadores rurais tem feito um grande esforço para adquirir uma área própria (embora de tamanho bem exíguo), também que parte dos filhos de agricultores familiares buscaram o acesso à terra antes de ocorrer a partilha da 
herança. Esses novos agricultores, em sua maioria, compraram essas propriedades com recursos provenientes de muitos anos de trabalho em atividades agrícolas ou não agrícolas, pois tinham o sonho de ter seu pedaço de terra e dessa forma conquistar sua independência e autonomia enquanto agricultores familiares.

Em relação aos agricultores pesquisados, que receberam a propriedade como herança, predominou a partilha igualitária, considerada a maneira correta e satisfatória de dividir os bens, segundo os entrevistados, tanto que pretendem agir da mesma quando ocorrer a sucessão com seus filhos. Do total de herdeiros, somente pouco mais da metade se mantiveram a propriedade, sendo que a quase totalidade dos agricultores pesquisados que herdaram parte da terra dos pais (embora a maioria cite que herdou "do pai") já trabalhava e morava na propriedade.

Entre os novos agricultores predominaram aqueles que consideram positivas as mudanças (que ocorreram em suas vidas e/ou na produção), após se tornarem agricultores por conta própria, sendo que o aumento da renda e a autonomia foram justamente os fatores destacados com maior frequência pelos pesquisados.

\section{AGRADECIMENTOS}

Ao CNPq pela concessão de auxílio pesquisa (Edital Universal).

\section{REFERÊNCIAS BIBLIOGRÁFICAS}

ALMEIDA, M. W. B. Redescobrindo a família rural. Revista Brasileira de Ciências Sociais, São Paulo, v. 1, n. 1, p.66-83, 1986.

ALVES, M. A. A “conquista da terra”: (re)produção Social e (re)construção histórica entre agricultores familiares do município de Araponga - MG. Mana, Rio de Janeiro, v. 12, n. 2, p.269-283, 2006.

ANJOS, F. S.; CALDAS, N. V. Pluriatividade e sucessão hereditária na agricultura familiar. In: SCHNEIDER, S. A diversidade da Agricultura Familiar. 2. ed. Porto Alegre: UFRGS, 2009. cap. 7, p. 186-212.

BATTESTIN, S. Ser jovem e ser agricultor: a agricultura familiar como perspectiva e projeto de vida para filhas e filhos de agricultores do município de Anchieta-ES. 2009. $206 \mathrm{f}$. Dissertação (Mestrado em Extensão Rural) - Universidade Federal de Viçosa, Viçosa, 2009.

BRASIL. Lei $\mathbf{N}^{\mathbf{0}}$ 11.326, de 24 de julho de 2006. Estabelece as diretrizes para a formulação da Política Nacional da Agricultura Familiar e Empreendimentos Familiares Rurais. Brasília, DF, 2006. Disponível em: http://www.planalto.gov.br/ccivil_03/_ato20042006/2006/lei/111326.htm Acesso em: 02 jun. 2018.

BUAINAIN, A. M.; ALVES, E.; SILVEIRA, J. M.; NAVARRO, Z. Sete teses sobre o mundo rural brasileiro. In: BUAINAIN, A.; M. ALVES, E.; SILVEIRA, J.M.; NAVARRO, Z. (Ed. Técnicos). O Mundo Rural do Brasil no Século 21. Brasília: Embrapa, 2014.

p.1160-1182. 
CAMARA, R. H. Análise de conteúdo: da teoria à prática em pesquisas sociais ligadas a organizações. Gerais: Revista Interinstitucional de Psicologia, São João del-Rey, v. 6, n. 2, p.179-191, 2013.

CAMARANO, A. A.; ABRAMOVAY, R. Êxodo rural, envelhecimento e masculinização no Brasil: panorama dos últimos 50 anos. Rio de Janeiro: Ipea, 1999. 28 p. (Texto para discussão, n. 621).

CARNEIRO, M. J. Herança e gênero entre agricultores familiares. Estudos Feministas, Florianópolis, v. 9, n. 1, p.22-55, 2001. Disponível em: http://www.scielo.br/pdf/ref/v9n1/8602.pdf. Acesso em: 18 abr. 2013.

CASTRO, L. F. P. Agricultura familiar, identidade social e arrendamentos rurais: a dimensão do "habitus" no acesso contratual à terra. Revista de Sociologia, Antropologia e Cultura Jurídica, Brasília, v. 3, n. 1, p.58-78, 2017.

FAVARETO, A. Paradigmas do Desenvolvimento Rural em questão. São Paulo: Iglu, 2007. 220 p.

FERRARI, D. L.; ABRAMOVAY, R.; SILVESTRO, M. L.; MELLO, M.A.; TESTA, V. M. Dilemas e estratégias dos jovens rurais: ficar ou partir? Estudos Sociedade e Agricultura, Rio de Janeiro, v. 12, n. 2, p.237-271, 2004.

GAlindo, E.; RESEnde, G. M.; CASTRO, C.; CRAVO, T. A. Programa Nacional De Crédito Fundiário (PNCF): uma avaliação de seus impactos regionais. Brasília: IPEA, 2015. 38 p. (Texto para discussão 2042)

GALIZONI, F. M. A terra construída: família, trabalho, ambiente e migrações no Alto Jequitinhonha, Minas Gerais. 2000. 98 f. Dissertação (Mestrado em Antropologia Social) Universidade de São Paulo, São Paulo, 2000.

GIL, A. C. Métodos e técnicas de pesquisa social. 6. ed. São Paulo: Atlas, 2008. 216 p.

HELFAND, S. M.; PEREIRA, V. F.; SOARES, W. L. Pequenos e médios produtores na agricultura brasileira - Situação atual e perspectivas. In: BUAINAIN, A. M.; ALVES, E.; SILVEIRA, J.M.; NAVARRO, Z. (Ed. Técnicos) O Mundo Rural do Brasil no Século 21. Brasília: Embrapa, 2014. Parte 4, cap. 1, p. 533-557.

JUCHEM, D. M.; BOSCARIN, P.; CÉSPEDES, E. A. H. Principais problemas enfrentados na hora da sucessão na propriedade rural: evidências empíricas. In: SEMINÁRIOS EM ADMINISTRAÇÃO FEA-USP, 8, 2005, São Paulo. Anais [....] São Paulo: USP, 2005. p. 113.

Disponível

em: http://www.ead.fea.usp.br/Semead/8semead/resultado/trabalhosPDF/92.pdf. Acesso em: 4 abr. 2013.

LAMARCHE, H. (Coord.) A agricultura familiar: uma realidade multiforme. Campinas: Ed. da UNICAMP, 1993. v. 1, 336 p.

MAIA, A. H.; SANT'ANA, A. L.; SILVA, F. C. Políticas Públicas de Acesso à Terra: uma análise do Programa Nacional de Crédito Fundiário, em Nova Xavantina (MT). Revista Economia Sociologia Rural. Brasília, v. 56, n. 2, p.311-328, 2018. Disponível em: 
http://www.scielo.br/scielo.php?script=sci_arttext\&pid=S0103-

$20032018000200311 \& \operatorname{lng}=$ pt\&nrm=iso. Acesso em: $13 \mathrm{dez} .2018$.

MARTINE, G. A trajetória da modernização agrícola: a quem beneficia? Lua Nova, São Paulo, n. 23, p.7-37, 1991. Disponível em: https://www.scielo.br/pdf/ln/n23/a03n23.pdf Acesso em: 01 abr. 2020.

MATTE, A.; SPANEVELlO, R. M.; ANDREATTA, T. Perspectivas de sucessão em propriedades de pecuária familiar no município de Dom Pedrito - RS. Holos, Natal, v. 1, p.144-159, 2015.

MATTEI, L. Considerações acerca de teses recentes sobre o mundo rural brasileiro. Revista de Economia e Sociologia Rural, Piracicaba, v. 52, supl. 1, p.S105-S124, 2014.

MENDONÇA, K. F. C.; RIBEIRO, A. E. M.; GALIZONI, F. M. Sucessão na agricultura familiar: estudo de caso sobre o destino dos jovens do alto Jequitinhonha, MG. In: ENCONTRO NACIONAL DE ESTUDOS POPULACIONAIS, 16, 2008, Caxambu. Anais [.... Caxambu: Associação Brasileira de Estudos Populacionais, 2008. p. 1-20. CD-ROM.

MENEZES, M.; MALAGODI, E. A.; MARQUES, F. R. S. Juventude e Educação em Assentamentos do Brejo Paraibano. In: FERRANTE, V. L. B.; WHITAKER, D. (Org.). Reforma Agrária e Desenvolvimento: desafios e rumos das políticas de assentamentos rurais. Brasília / São Paulo: NEAD/MDA; UNIARA, 2008. Parte 2, cap. 2, p. 131-150.

MENDRAS, H. Sociedades camponesas. Rio de Janeiro: Zahar, 1978. 265 p.

MÜLLER, G. São Paulo - o núcleo do padrão agrário moderno. In: STÉDILE, J. P. (Org.) A questão agrária na década de 90. 4. ed. Porto Alegre: UFRGS, 2004. Parte 3, cap. 1, p. 221237.

PAULILO, M. I. Movimento de mulheres agricultoras: terra e matrimônio. Cadernos de Pesquisa Interdisciplinar em Ciências Humanas, Florianópolis, v. 2, n. 21, p.1-18, 2000.

PETINARI, R. A.; BERGAMASCO, S. P. P.; TERESO, M. J. A. Estratégias de reprodução social de agricultores familiares da região de Jales-SP. In: CONGRESO LATINOAMERICANO DE SOCIOLOGIA RURAL, 8, 2010, Porto de Galinhas. Anais [....] Porto de Galinhas: ALASRU, 2010. p. 1-20. CD-ROM.

SANT'ANA, A. L. Raízes na terra: as estratégias dos produtores familiares de três municípios da mesorregião de São José do Rio Preto (SP). Araraquara (SP), 2003. 246 f. Tese (Doutorado em Sociologia) - Faculdade de Ciências e Letras, Universidade Estadual Paulista, Araraquara.

SANT'ANA, A. L. Estratégias dos agricultores familiares: entre a moldagem da intensificação produtiva e a construção de formas diferenciadas de comercialização. Retratos de Assentamentos, Araraquara, v. 14, n. 1, p.283-304, 2011.

SANT'ANA, A. L.; TARSITANO, M. A. A.; SILVA, F. C.; MODENESE, V. S.; PICOLI, P. R. Significado da terra para os assentados da região de Andradina-SP. In: SIMPÓSIO SOBRE REFORMA AGRÁRIA E ASSENTAMENTOS RURAIS, 3, 2008, Araraquara (SP). Anais [.... Araraquara (SP): Uniara, 2008. 1 CD-ROM. 
SANT’ANA, A. L.; SILVA, F. C.; SANT’ANA, D. Z. Sistemas de produção dos agricultores familiares da microrregião de Jales (SP, Brasil) e as políticas públicas. In: CONGRESSO DA SOCIEDADE LATINOAMERICANA DE SOCIOLOGIA RURAL, 9, Cidade do México (México). Analles [....] Cidade do México: ALASRU, 2014. 1 CD-ROM.

SÃO PAULO. Secretaria de Agricultura e Abastecimento do Estado de São Paulo. Instituto de Economia Agrícola. Coordenadoria de Desenvolvimento Rural Sustentável. Projeto LUPA 2007/2008: Censo Agropecuário do Estado de São Paulo. São Paulo: SAA / IEA / CDRS, 2008. Disponível em: http://www.cdrs.sp.gov.br/projetolupa/. Acesso em: 17 jun. 2013.

SCHWARTZ, L. H.; SALAMONI, G. Organização e reprodução social da agricultura familiar entre descendentes de imigrantes pomeranos no município de São Lourenço do Sul, RS. In: ENCONTRO NACIONAL DE GEOGRAFIA AGRÁRIA, 19, 2008, São Paulo. Anais [.... São Paulo: USP, 2009. p.1-23.

SILVESTRO, M. L.; ABRAMOVAY, R.; MELLO, M. A.; DORIGON, C.; BALDISSERA, I. T. Impasses sociais da sucessão hereditária na agricultura familiar. Florianópolis (SC) Brasília: Epagri; NEAD/MDA, 2001. 102 p.

SPANEVEllO, R. M.; MATTE, A.; AZEVEDO, L. F.; ANDREATTA, T. As perspectivas sucessórias de gestão dos negócios e do patrimônio entre agricultores familiares sem sucessores. Revista CCEI, Bagé, v. 14, n. 26, p.53-71, 2010.

SPANEVELLO, R. M.; AZEVEDO, L. F.; VARGAS, L. P.; MATTE, A. A migração juvenil e implicações sucessórias na agricultura familiar. Revista de Ciências Humanas, Florianópolis, v. 45, n. 2, p.291-304, 2011.

VINUTO, J. A amostragem em bola de neve na pesquisa qualitativa: um debate em aberto. Temáticas, Campinas, v. 22, n. 44, p.203-220, 2014.

WANDERLEY, M. N. B. Raízes históricas do campesinato brasileiro. In: TEDESCO, J. C. (Org.) Agricultura familiar: realidades e perspectivas. Passo Fundo: EDIUPF, 1999. cap. 1, p. 23-56.

WANDERLEY, M. N. B. O agricultor familiar no Brasil: um ator social da construção do futuro. In: PETERSEN, P. (Org.) Agricultura familiar camponesa na construção do futuro. Rio de Janeiro: AS-PTA, 2009. cap. 2, p. 33-45.

WEISHEIMER, N. A situação juvenil na agricultura familiar. 2009. 331 f. Tese (Doutorado em Sociologia) - Universidade Federal do Rio Grande do Sul, Porto Alegre.

WOORTMANN, E. F. Herdeiros, parentes e compadres. São Paulo / Brasília: Hucitec / Edunb, 1995. 336 p. 